\title{
Further observations on Mima polymorpha and Achromobacter (Bacterium) anitratum
}

\author{
J. BRODIE AND A. HENDERSON \\ From the Laboratory, City Hospital, Aberdeen
}

SYNOPSIS Further investigations on the morphology, biochemical reactions, and serological relationships of strains of Mima polymorpha and Achromobacter (Bacterium) anitratum are reported. The results seem to indicate such a close relationship that it may yet be necessary to reconsider the nomenclature of these organisms.

In 1963, Brodie and Henderson reported investigations on two strains of Mima polymorpha and the results of a limited comparative study of these in relation to four strains of Achromobacter (Bacterium) anitratum. A further 16 isolations of Mima polymorpha have since been obtained in this area and have made possible a wider biochemical and serological study of all 18 Mima strains and seven further strains of Achromobacter anitratum.

\section{MATERIALS, METHODS, AND RESULTS}

STRAINS Information regarding the source of the strains of Mima polymorpha is given in Table I. The N.C.T.C. references for the strains of Achromobacter (Bacterium) anitratum are $7250,7412,7422,7461,7844,8698$, and 9427.
BIOCHEMICAL AND MORPHOLOGICAL INVESTIGATIONS The fermentative properties were read after incubation at $37^{\circ} \mathrm{C}$. for 10 days in peptone water containing the relevant chemical, using bromothymol blue as indicator. Production of indole, ammonia, and catalase was determined after incubation for 10 days in peptone water, then adding Kovac's reagent, Nessler's reagent, and hydrogen peroxide respectively. Colonies, on nutrient agar plates after 24 hours' incubation, were tested for oxidase activity by adding a $1 \%$ solution of tetramethyl-pphenylenediamine hydrochloride. Urease activity was assessed on the urea agar of Christensen (1946). Phosphatase production was determined by exposing colonies, grown on nutrient agar containing $0.01 \%$ phenolphthalein phosphate, to ammonia vapour (Barber and Kuper, 1951). The results are listed in Table II.

PREPARATION OF ANTISERA As strains were isolated continuously throughout the investigation, only the first

TABLE I

\begin{tabular}{|c|c|c|c|c|c|}
\hline \multirow{3}{*}{ Strain } & \multirow{3}{*}{ Source } & \multicolumn{3}{|c|}{ SOURCES OF AND INFORMATION CONCERNING MIMA STRAINS } & \multirow{3}{*}{ Other Organism $(s)$ Isolated } \\
\hline & & \multicolumn{2}{|c|}{ Patients } & \multirow[t]{2}{*}{ Clinical Summary } & \\
\hline & & $\operatorname{Sex}$ & Age & & \\
\hline $\begin{array}{l}{ }^{1} \mathrm{~V} 16290^{2} \\
{ }^{1} \mathrm{D} 8460\end{array}$ & Wound & $\mathbf{M}$ & 29 & Post-operative infection & \multirow{17}{*}{$\begin{array}{l}\text { Staph. pyogenes } \\
\text { Staph. epidermidis } \\
\text { None } \\
\text { None } \\
\text { None } \\
\text { None } \\
\text { None } \\
\text { None } \\
\text { Candida sp. } \\
\text { None } \\
\text { E. coli } \\
\text { None } \\
\text { None } \\
\text { \{andida rugosa } \\
\text { Cryptococcus neoformans } \\
\text { Citrobacter freundii } \\
\text { Staph. pyogenes, Aspergillus sp. } \\
\text { Staph. epidermidis } \\
\text { E. coli, Strep. faecalis } \\
\text { Staph. pyogenes }\end{array}$} \\
\hline 'D8460 & Nose & $\mathbf{F}$ & 42 & Routine check before chest surgery & \\
\hline${ }^{2} \mathrm{~V} 18520$ & Ear & $\mathbf{F}$ & 13 & External otitis & \\
\hline AR748Q & Urethra & $\mathbf{M}$ & 29 & Suspected gonorrhoea & \\
\hline V20757 & Vagina & $\mathbf{F}$ & 50 & Leucorrhoea & \\
\hline${ }^{1} \mathrm{~V} 19465$ & Cervix uteri & $\mathbf{F}$ & 35 & Leucorrhoea & \\
\hline D9900 & Throat & $\mathbf{F}$ & $7 / 12$ & Upper respiratory tract infection & \\
\hline${ }^{1} \mathrm{D} 9682$ & Throat & $\mathbf{M}$ & 24 & Sore throat & \\
\hline 'V16870 & Wound & $\mathbf{M}$ & 84 & Post-operative infection & \\
\hline${ }^{1} \mathrm{~V} 18516$ & Placenta & $\mathbf{F}$ & 27 & Stillbirth & \\
\hline 'V17750 & Wound & $\mathbf{M}$ & 84 & Post-operative infection & \\
\hline 'V19677 & Cervix uteri & $\mathbf{F}$ & 35 & Leucorrhoea & \\
\hline $\mathrm{U} 28090$ & Urine & $\mathbf{F}$ & 55 & Cystitis following hysterectomy & \\
\hline S28366 & Sputum & $\mathbf{M}$ & 80 & Respiratory infection & \\
\hline $\begin{array}{l}\text { V21612 } \\
\text { V21784 }\end{array}$ & $\begin{array}{l}\text { Wound } \\
\text { Wound }\end{array}$ & $\begin{array}{l}\mathbf{M} \\
\mathbf{F}\end{array}$ & $\begin{array}{l}35 \\
66\end{array}$ & $\begin{array}{l}\text { Infected compound fracture of tibia (Russian seaman) } \\
\text { Post-operative infection }\end{array}$ & \\
\hline 'V19738 & Vagina & $\mathbf{F}$ & 28 & Puerperal fever & \\
\hline${ }^{1} \mathrm{~V} 16578^{2}$ & Wound & $\mathbf{M}$ & 57 & Osteomyelitis & \\
\hline
\end{tabular}

${ }^{1}$ Strains used to prepare antisera.

'Strains previously reported (Brodie and Henderson, 1963). 
TABLE II

COMPARISON OF PROPERTIES OF STRAINS OF MIMA AND B. ANITRATUM

Morphology coccoid

Growth on

Nutrient agar

Horse blood agar

MacConkey's agar

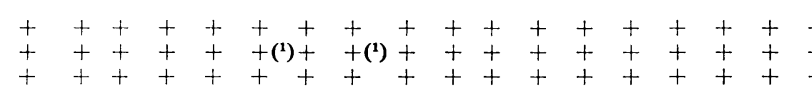

Motility

Aerobic (strict)

Gelatin liquefaction

Catalase

Oxidase

Phosphatase

Urease

Indole

Methyl red test

Voges-Proskauer test

Citrate utilization

Nitrite production

Ammonia

Hydrogen sulphide

Carbohydrates

Pentoses

Arabinose

Xylose

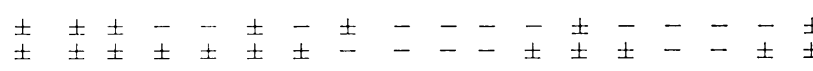

Hexoses

Rhamnose

Fructose

Galactose

Mannose
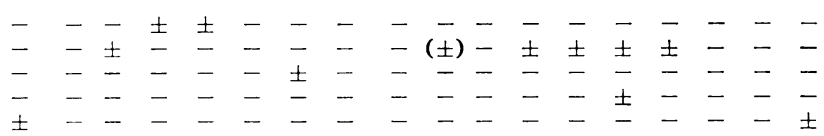

Disaccharides

Sucrose

Maltose

Lactose

Trehalose

Trisaccharide

Raffinose

Polysaccharides

Inulin

Dextrin

Alcohols

Glycerol

Adonitol

Mannitol

Dulcitol

Sorbitol

Glycosides

Salicin

Aesculin

Inositol

$+=$ reaction obtained

$(t)=$ reaction weak after seven days

$\pm=$ acid produced without gas

$( \pm)=$ initially acid produced then reversion to neutrality

( $\left.{ }^{1}\right)$ = beta haemolysis 
TABLE III

TUBE AGGLUTINATION TITRES OF 11 MIMA ANTISERA TESTED AGAINST MIMA POLYMORPHA AND STRAINS OF ACHROMOBACTER (BACTERIUM) ANITRATUM

Suspension of Strain Antiserum to Strain Pattern of

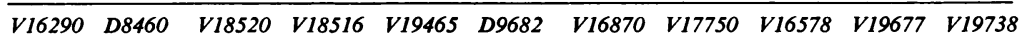
Agglutination

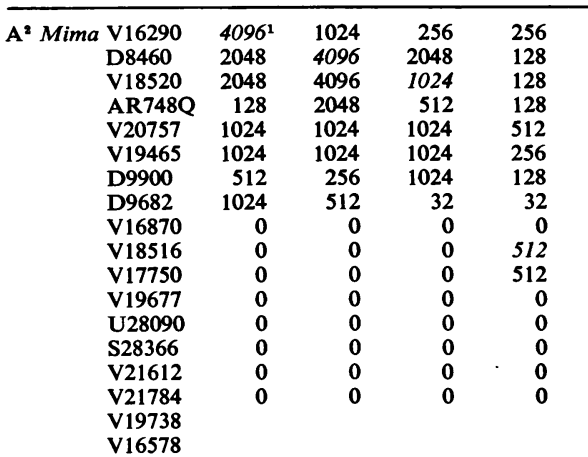

$\begin{array}{rrr}4 & 8 & 0 \\ 8 & 8 & 0 \\ 16 & 32 & 0 \\ 8 & 16 & 0 \\ 4 & 0 & 0 \\ 2048 & 2048 & 0 \\ 2048 & 2048 & 0 \\ 2048 & 2048 & 8 \\ 2048 & 2048 & 2048 \\ 0 & 0 & 0 \\ 0 & 0 & 0 \\ 0 & 0 & 0 \\ 0 & 0 & 0 \\ 0 & 0 & 0 \\ 0 & 0 & 0 \\ 0 & 0 & 0 \\ \text { Autoagglutinable } & \\ \text { Autoagglutinable } & \end{array}$

$\begin{array}{rr}0 & 0 \\ 0 & 0 \\ 0 & 0 \\ 0 & 0 \\ 0 & 0 \\ 0 & 0 \\ 0 & 0 \\ 0 & 0 \\ 0 & 0 \\ 256 & 1024 \\ 128 & 1024 \\ 0 & 0 \\ 0 & 0 \\ 0 & 0 \\ 0 & 0 \\ 0 & 0\end{array}$

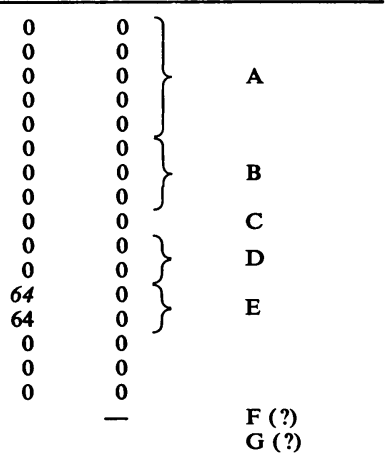

$\mathrm{B}^{2}$ Achromobacter

N.C.T.C. 9427

N.C.T.C. 7461

N.C.T.C. 7412

$\begin{array}{llll}2048 & 4096 & 2048 & 128\end{array}$

$\begin{array}{rr}128 & 16\end{array}$

$16 \quad 32$

$2048 \quad 2048$

128

$64 \quad 512$

N.C.T.C. 7844

N.C.T.C. 7250

N.C.T.C. 8698

2048

512

512
1024

32

32

N.C.T.C. 7422

128
0

1024

64

64
32
32
32
8
0

8
32
8
16
16
0
0

0
128
64
128
64
0
0

0
1024
1024
1024
2048
0
0

4
32
32
32
32
32
64

8
2048
512
1024
2048
0
8

$\mathbf{A}$

${ }^{1}$ Titre is expressed as the reciprocal of the final dilution giving complete agglutination of the bacterial suspensions.

${ }^{2} \mathrm{~A}, 18$ strains of Mima polymorpha and B, seven strains of Achromobacter (Bacterium) anitratum.

11 Mima strains isolated were used for the preparation of antisera. These are appropriately marked in Table I. Each strain was grown on nutrient agar for 24 hours, washed off and suspended in $0.2 \%$ formal saline, then diluted with saline to the opacity of Brown's tube no. 4 (Brown, 1919). Adult rabbits were inoculated intravenously on the first three days of each of three consecutive weeks, using the following doses:- $0.2 \mathrm{ml}$., $0.4 \mathrm{ml}$., $0.8 \mathrm{ml}$., $0.8 \mathrm{ml}$., $1.0 \mathrm{ml}$., $1.0 \mathrm{ml}$., $1.0 \mathrm{ml}$., $1.0 \mathrm{ml}$., and $1.0 \mathrm{ml}$. After a further five days' rest, the rabbits were bled out under pentobarbitone anaesthesia. The serum was separated, inactivated at $56^{\circ} \mathrm{C}$. for 20 minutes, then merthiolate added to a final concentration of $1 / 10,000$. The antisera were stored at $-20^{\circ} \mathrm{C}$.

TUBE AGgLUtination TESTS Suspensions of each of the 25 strains of organisms, in the live state and diluted to the opacity of Brown's tube no. 4, were tested against each of the 11 Mima polymorpha antisera. Agglutination was allowed to take place in tubes in a water bath at $56^{\circ} \mathrm{C}$. for four hours, then the tubes allowed to stand overnight at room temperature. The results are set out in Table III.

\section{DISCUSSION}

The first account of an unusual Gram-negative coccus causing meningitis was given by Sen in 1936, but a systematic search for these organisms was not made until 1939, when de Bord described a group of organisms in normal and diseased conjunctivae and vaginas which he named Mima. Numerous instances of the isolation of this group of bacteria from pathological materials have now been recorded and an account of these was given in a previous publication by Brodie and Henderson (1963).

A further group of pleomorphic organisms, sometimes cocci, sometimes coccobacilli and usually Gram-negative, was described by Schaub and Hauber (1948) and named Bacterium (Achromobacter) anitratum. In 1949, Ewing suggested that Mima polymorpha and Achromobacter anitratum might be related.

The previous findings of Brodie and Henderson (1963) on the two strains of Mima polymorpha, V16290 and V16578, and four strains of Achromobacter (Bacterium) anitratum, N.C.T.C. nos. 7362, 7363,7364 , and 8102 , suggested that on morphological grounds Mima is mainly coccoid and the four $B$. anitratum strains mainly bacillary. Now, however, with the number of Mima strains increased to 18 and these compared biochemically and morphologically with a further seven $B$. anitratum strains (Table II) little, if any, evidence is forthcoming suggesting their entitlement to separate names.

The serology of Mima polymorpha has been investigated by Cary, Lindberg, and Faber (1956). Using a precipitin technique, after extracting the bacteria by the method of Maxted (1948), 29 strains 
were examined. These investigators found evidence of the existence of 19 serotypes, distinguished by type-specific antigens, but found no evidence of group-reacting antigens.

In the present study of agglutinogens, 18 strains of Mima have been agglutinated against 11 Mima antisera (Table III, A). Certain 'patterns of agglutination'-A, B, C, D, and E-have appeared. Five strains fell within pattern $A$, three in $B$, one in $C$, two in D, and two in E. Two strains, V19738 and V16578, unfortunately were autoagglutinable. Of V16578 it is known from past work that it had agglutinated with antiserum to strain V16290 to a dilution of 1 in 8,192 (Brodie and Henderson, 1963), and this evidence, together with the reasonable assumption that, in the saline-stable state, it would agglutinate with its homologous serum, suggests that its reactions would constitute yet another pattern. Again, since the antiserum to V19738 fails to agglutinate any of the 16 stable suspensions and would be expected to agglutinate its homologue when saline-stable, the resultant agglutination pattern would be different from the others. Thus, patterns $\mathrm{A}, \mathrm{B}, \mathrm{C}, \mathrm{D}$, and $\mathrm{E}$ are demonstrable with the antisera and strains available and the further patterns $F$ and $G$ seem feasible. The three remaining strains of the 18 tested failed to react with any of the 11 antisera, providing almost certain evidence that further serotypes exist, as the work of Cary et al. (1956) would indicate.

As previously reported by Brodie and Henderson (1963), absorption of antiserum to Mima strain V16290 with all four of the previously examined strains of B. anitratum, N.C.T.C. nos. 7462,7463 , 7464 , and 8102 , resulted in no drop in titre, suggesting then that these strains of $B$. anitratum were unrelated serologically to Mima. Now, with seven further strains of $B$. anitratum tested against 11 Mima antisera (Table III, B), it is evident that a serological relationship does exist. Indeed, two of the 'patterns of agglutination' obtained with Mima antisera against Mima strains, namely patterns and $\mathrm{E}$, have been reproduced with $B$. anitratur strains, N.C.T.C. no. 9427 giving pattern A an\& N.C.T.C. no. 8698 with N.C.T.C. no. 7422 yielding pattern $\mathrm{E}$. The remaining four strains give agglutin ation with almost all the Mima antisera. If the previously examined strains of $B$. anitratum ha\& possessed antigen(s) as in patterns A or B or haक shown the wide range of reactions of the present four strains mentioned above, absorption of pattern A Mima antiserum V16290 would have bee $\vec{B}$ demonstrated. It seems, therefore, that the origina? four strains, examined by Brodie and Henderson if 1963, might have been in pattern E group, or some other group as yet not defined, and on this accounit have failed to indicate a serological relationship.

The present results indicate a far closer relation $\vec{\omega}$ ship in morphology, biochemical, and serologicat reactions than was at first apparent, so lending support to the suggestion of Ewing (1949) thas Mima polymorpha and Achromobacter (Bacterium anitratum might be related.

If these groups of organisms are regarded finall/ as related, there will arise the problem of a name. By the principle of prior names, one would expech the name of the group to continue to be Mimat Many investigators, however, have described pathog genic organisms under the name of Achromobactes (Bacterium) anitratum and, if the principle of the nomen conservandum is employed, it is possible the the latter name will be applied.

\section{REFERENCES}

Barber, M., and Kuper, S. W. A. (1951). J. Path. Bact., 63, 65. Brodie, J., and Henderson, A. (1963). J. clin. Path., 16, 49. Brown, H. C. (1919). Indian. J. med. Res., 7, 238.

Cary, S. G., Lindberg, R. B., and Faber, J. E. Jr. (1956). J. Bact 72, 728.

Christensen, W. B. (1946). Ibid., 52, 461.

De Bord, G. G. (1939). Ibid., 38, 119.

Ewing, W. H. (1949). Ibid., 57, 659.

Maxted, W. R. (1948). Lancet, 2, 255.

Schaub, I. G., and Hauber, F. D. (1948). J. Bact., 56, 379.

Sen, B. B. (1936). Ibid., 32, 293. 